\title{
Using an Ammonia Treatment to Improve the Floating-Gate Spacing in Split-Gate Flash Memory
}

\author{
Wen-Ting Chu, Hao-Hsiung Lin, Yeur-Luen Tu, Yu-Hsiung Wang, Chia-Ta Hsieh, Hung-Cheng Sung, \\ Yung-Tao Lin, Member, IEEE, Chia-Shiung Tsai, and Chung S. Wang, Member, IEEE
}

\begin{abstract}
In the split-gate flash memory process, during poly oxidation, the bird's beak encroaches under the SiN film, especially along the poly grain boundary, and that will cause nonuniform floating-gate (FG) spacing, even bridging, which is an obstacle to cell shrinkage. In this paper, we show that employing an ammonia treatment on the poly can nitridize the poly surface, thereby avoiding bird's beak bridging. After the ammonia treatment, FG spacing is quite uniform and can be improved from 0.09 to 0.03 $\mu \mathrm{m}$. The XPS analysis on the ammonia treated poly shows the oxynitride thickness is less than $5 \mathbf{~ n m}$.
\end{abstract}

Index Terms-Ammonia, bird's beak, flash memory, floatinggate.

\section{INTRODUCTION}

$\mathbf{R}$ ECENTLY, Flash EEPROM has become increasing popular for use in portable applications. The need of low-power consumption and high density is preferable and often inevitable. When compared with the stack-gate cell, a split-gate cell not only has immunity from over-erase [4], but can also adopt a field-enhanced structure to further reduce its erase voltage, that is, reduce operation power [1]-[3], [5]. Therefore, the application of such a split-gate cell in portable systems is very promising. However, when the floating-gate (FG) poly is being oxidized (to create a field-enhanced structure), the bird's beak will encroach under the SiN layer, especially along the poly-grain boundary. Since the poly-grain is randomly distributed, the encroaching bird's beak may form a cusp-like structure and result in nonuniform FG spacing which may deteriorate the uniformity of the cell performances especially for devices with FG spacing of less than $0.09 \mu \mathrm{m}$. Even for cells with smaller spacing, bridging between the FGs occurs on occasion. In this study, we found that the native oxide on the poly surface is responsible for the unexpectedly longer bird's beak. Using an ammonia $\left(\mathrm{NH}_{3}\right)$ treatment to nitridize the poly surface can inhibit the occurrence of the cusp-like structure along the grain boundary.

\section{DEVICE FABRICATION}

A 0.18- $\mu$ m dual-poly-Si CMOS technology was used to fabricate the split-gate flash cell with a field-enhanced structure [2],

Manuscript received May 19, 2004; revised June 4, 2004. The review of this letter was arranged by Editor C.-P. Chang.

W.-T. Chu and H.-H. Lin are with the Department of Electrical Engineering and Graduate Institute of Electronic Engineering, National Taiwan University, Taipei, Taiwan, R.O.C. (e-mail: wtchu@epicenter.ee.ntu.edu.tw).

Y.-L. Tu, Y.-H. Wang, C.-T. Hsieh, H.-C. Sung, Y.-T. Lin, C.-S. Tsai, and C. S. Wang are with the Non-volatile Memory Division, Taiwan Semiconductor Manufacturing Company, Ltd., Science-Based Industrial Park, Hsinchu, Taiwan 300, R.O.C.

Digital Object Identifier 10.1109/LED.2004.833825
[3]. ([3, Fig. 1] shows the detailed process flow with step by step cross-section diagram). After depositing the poly-Si on the FG oxide, an $\mathrm{NH}_{3}$ treatment [6] was employed before the $\mathrm{SiN}$ layer deposition. The FG area was then defined by photolithography and the $\mathrm{SiN}$ was removed by dry etching. Polysilicon oxidation was performed to generate a bowl-shaped poly structure. After removing the SiN film, a poly etch was performed using poly-oxide as a hard mask, creating an FG with a sharp tip structure. Inter-poly-oxide (IPO) was then deposited to form both the tunneling oxide and the CG oxide. Finally, the CG was formed by depositing and patterning the second poly-Si. For comparison, another wafer underwent all the same processes except the $\mathrm{NH}_{3}$ treatment.

\section{RESUlTS AND DISCUSSION}

In-line SEM inspection at the FG-poly-etch stage was used to verify the FG-to-FG bridging issue. In Fig. 1(a), the first column shows the nominal FG spacing. Wafers that did not undergo an $\mathrm{NH}_{3}$ treatment have many cusp-like structures. The cusp-like structure is a result of the oxide encroaching beneath the $\mathrm{SiN}$ film [the long bird's beak shown in Fig. 1(b)] when the poly is oxidized. It causes nonuniform FG spacing, or, even worse, FG bridging in the region with a smaller FG spacing, as can be seen in the figure. For wafers having $950{ }^{\circ} \mathrm{C}, 30 \mathrm{~s}, \mathrm{NH}_{3}$ treatment (RTN) before the SiN deposition, Fig. 1(a) shows a smooth FG shape and a uniform FG spacing due to the nitridized poly surface.

Furthermore, an 18-kb mini-array of FG-connected cells was designed to verify the FG bridging issue using electrical tests. Fig. 2 shows the relationship between the nominal FG spacing and the FG bridging current. Wafers having the $\mathrm{NH}_{3}$ treatment demonstrate a very low bridging current, even at $0.03-\mu \mathrm{m}$ FG spacing, but wafers without the ammonia treatment show a large FG bridging current when the FG spacing is less than $0.09 \mu \mathrm{m}$. Based on this data, it is believed that cells with FG spacing from 0.09 to $0.03 \mu \mathrm{m}$ can be improved by adding an $\mathrm{NH}_{3}$ treatment.

To further investigate the effect of the ammonia treatment (nitridation) on the poly surface, both treated and untreated samples were analyzed using XPS in order to understand the film composition and its thickness. The XPS data shown in Fig. 3(a) illustrates that the wafer with the $\mathrm{NH}_{3}$ treatment has nitrogenrelated peaks, but the untreated wafer does not. This implies that the treatment can nitridize the poly and convert the native $\mathrm{SiO}$ on the poly surface into $\mathrm{SiON}$, which can effectively retard the encroachment of the bird's beak along the poly grain boundary because the oxygen diffusivity is lower in SiON than in native oxide. The XPS-analyzed-depth for take-off angle of 


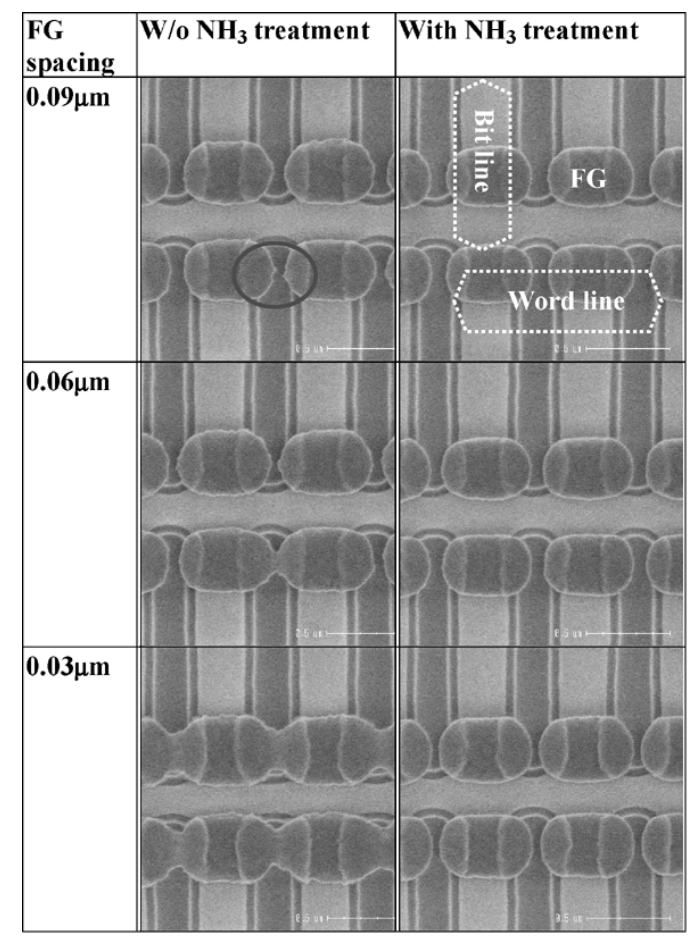

(a)

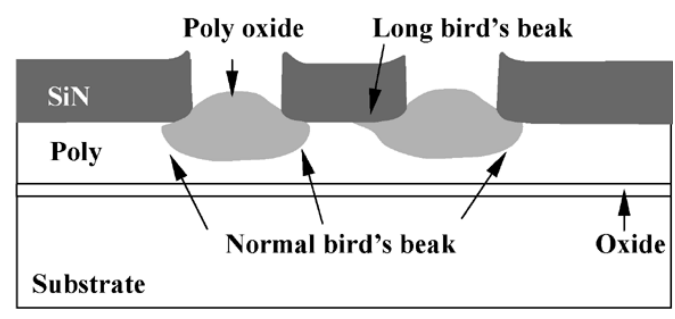

(b)

Fig. 1. (a) In-line SEM pictures for various nominal FG spacing. The circle indicates the cusp-like structures on the wafer without the $\mathrm{NH}_{3}$ treatment. (b) Cross-section illustrations for normal and long bird's beak after poly oxidation.

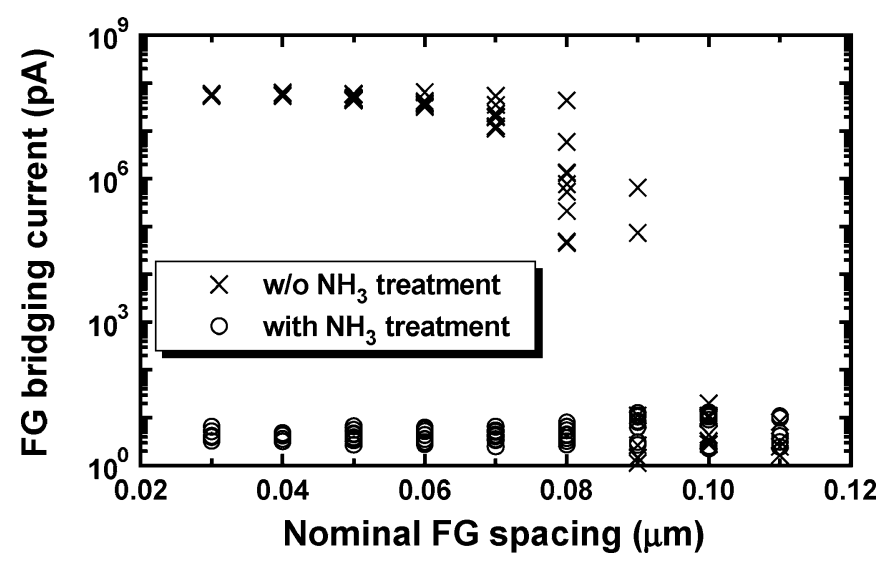

Fig. 2. FG bridging test electrical data on an 18-kb FG-connected mini-array for the $\mathrm{NH}_{3}$ treated and untreated wafers. The leakage current for the FG-bridging test is taken at $2.5 \mathrm{~V}$. When the bridging current is larger, the FG bridging becomes more serious.

$0^{\circ}$ is around $10 \mathrm{~nm}$ and that for take-off angle of $60^{\circ}$ is about $5 \mathrm{~nm}$. When comparing this data, summarized in Fig. 3(b), it

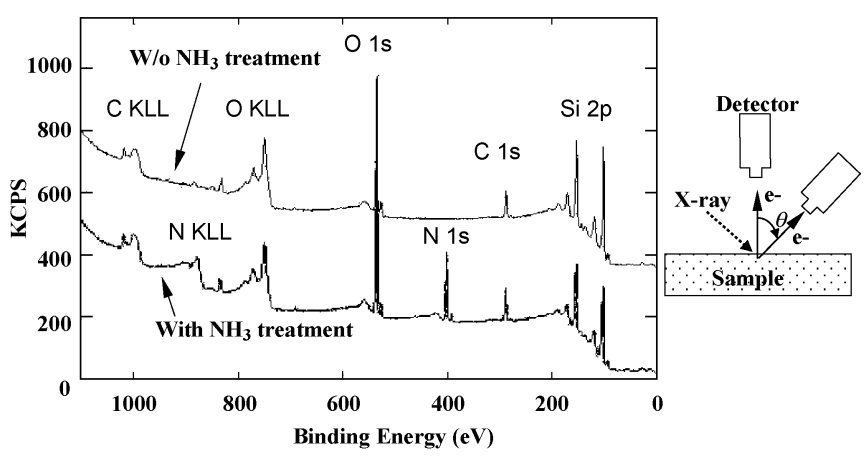

(a)

\begin{tabular}{|c|c|c|c|c|c|c|c|c|}
\hline $\begin{array}{c}\text { Take-off- } \\
\text { angle }\end{array}$ & $\begin{array}{c}\mathrm{NH}_{3} \\
\text { treatment }\end{array}$ & $\mathbf{O} \%$ & $\mathrm{~N} \%$ & $\mathrm{C} \%$ & $\mathrm{Si} \%$ & Si-Si \% & $\begin{array}{c}\text { Si-N or } \\
\text { O-Si-N \% }\end{array}$ & Si-O \% \\
\hline $\mathbf{0}^{\circ}$ & Yes & 23.2 & 15.6 & 13.6 & 47.2 & 28.6 & 10.9 & 7.7 \\
\hline $\mathbf{0}^{\circ}$ & No & 28.6 & $\mathbf{0}$ & 13.5 & 57.8 & 51.0 & $\mathbf{0}$ & 6.8 \\
\hline $6^{\circ}$ & Yes & 27.7 & 15.7 & 19.9 & 36.2 & 15.5 & 16.7 & 4.1 \\
\hline $\mathbf{6 0}^{\circ}$ & No & 35.5 & $\mathbf{0}$ & 21.4 & 42.7 & 33.0 & $\mathbf{0}$ & $\mathbf{9 . 6}$ \\
\hline
\end{tabular}

(b)

Fig. 3. (a) XPS results for both the $\mathrm{NH}_{3}$ treated and untreated samples. The take-off angle (" $\theta$ " in the right-hand picture) is $0^{\circ}$. Only the wafer with the $\mathrm{NH}_{3}$ treatment has the nitrogen $(\mathrm{N})$-related peaks. (b) XPS atomic concentration data summary for take-off angle of $0^{\circ}$ and $60^{\circ}$.

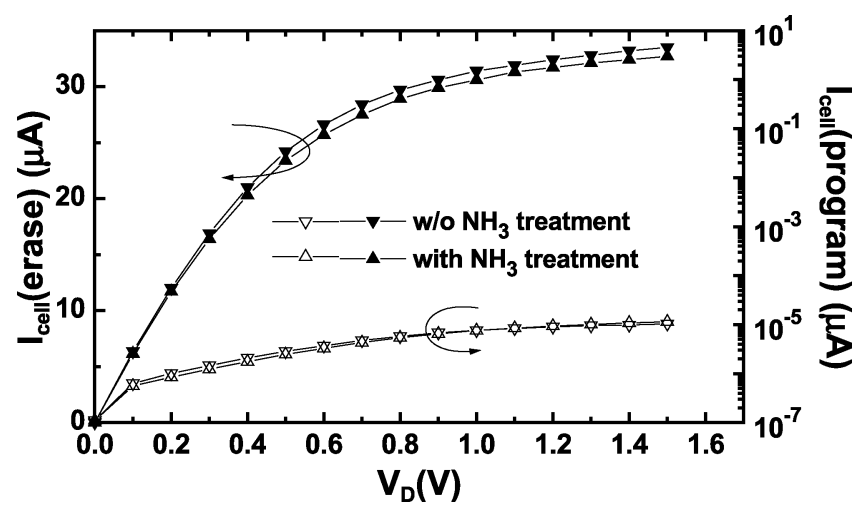

Fig. 4. Cell current for the wafers with and without $\mathrm{NH}_{3}$ treatment shows no obvious difference for both the programmed and erased state. Where the program condition is $\mathrm{V}_{\mathrm{WL}}=1.8 \mathrm{~V}, \mathrm{~V}_{\mathrm{D}}=0.7 \mathrm{~V}, \mathrm{~V}_{\mathrm{S}}=10 \mathrm{~V}$; the erase condition is $\mathrm{V}_{\mathrm{WL}}=12.5 \mathrm{~V}$; and the read condition is $\mathrm{V}_{\mathrm{WL}}=2.5 \mathrm{~V}, \mathrm{~V}_{\mathrm{S}}=$ $0 \mathrm{~V}$.

can be determined that the SiON film thickness should be less than $5 \mathrm{~nm}$ because the $\mathrm{Si}-\mathrm{Si}$ bonding still exists (15.5\%) in the case where the take-off angle is $60^{\circ}$.

As shown in Fig. 4, the cell current has no apparent degradation for both the programmed and erased state.

\section{CONCLUSION}

Using a poly-oxidation process to create a field-enhanced structure is a known approach to reducing the erase voltage. However, in this process, the bird's beak will encroach under the SiN film, especially along the poly-grain boundary, causing nonuniform FG spacing, or even FG bridging, which is an obstacle to cell shrinkage. According to in-line top-view SEM inspection and bridging test electrical data, FG spacing can be further reduced by $0.06 \mu \mathrm{m}$ after the introduction an $\mathrm{NH}_{3}$ treatment before the SiN film deposition. 


\section{ACKNOWLEDGMENT}

The authors would like to thank the members of the Nonvolatile Memory Program, R\&D Division, Taiwan Semiconductor Manufacturing Company, Ltd., for wafer fabrication, and Silicon Storage Technology Inc., Sunnyvale, CA, for their technical support.

\section{REFERENCES}

[1] K.-C. Huang, Y.-K. Fang, D.-N. Yaung, C.-W. Chen, H.-C. Sung, D.-S. Kuo, and C. S. Wang, "The impacts of control gate voltage on the cycling endurance of split gate flash memory," IEEE Electron Device Lett., vol. 21, pp. 359-361, July 2000.
[2] B. Yeh, "Single transistor non-volatile electrically alterable semiconductor memory device," U.S. Patent 5029 130, 1991.

[3] S. Kianian, A. Levi, D. Lee, and Y.-W. Hu, "A novel 3 volts-only, small sector erase, high density Flash E2 PROM," in Symp. VLSI Technol. Dig., 1994, pp. 71-72.

[4] K. Naruke, S. Yamada, E. Obi, S. Taguchi, and M. Wada, "A new flasherase EEPROM cell with a select-gate on its source side," in IEDM Tech. Dig., 1989, pp. 603-606.

[5] C.-H. Wang, M. Hemming, P. Klinger, A. V. Kordesch, C.-M. Liu, and K. Su, "On the cell misalignment for multilevel storage FLASH E EROM," in Symp. VLSI Technol. Dig., 1999, pp. 191-194.

[6] N. Ajika, M. Ohi, H. Arima, T. Matsukawa, and N. Tsubouchi, "Enhanced reliability of native oxide free capacitor dielectrics on rapid thermal nitrided polysilicon," in Symp. VLSI Technol. Dig., 1991, pp. 63-64. 